\title{
XLV. Genesis of ions by collision and sparking- potentials in carbon dioxide and nitrogen
}

\author{
H.E. Hurst B.A. B.Sc.
}

To cite this article: H.E. Hurst B.A. B.Sc. (1906) XLV. Genesis of ions by collision and sparkingpotentials in carbon dioxide and nitrogen , Philosophical Magazine Series 6, 11:64, 535-552, DOI: $10.1080 / 14786440609463469$

To link to this article: http://dx.doi.org/10.1080/14786440609463469

Published online: 16 Apr 2009.

Submit your article to this journal $₫$

Џ Article views: 2

Q View related articles $\square$

7 Citing articles: 7 View citing articles $\square$ 


\section{$[535$}

XLV. Genesis of Ions by Collision and Sparking-Potentials in Carbon dioxide and Nitrogen. By H. E. Hurst, B.A., B.Sc., Hertford College, Oxford *.

A $\mathrm{N}$ explanation of the theory of ionization by collisions. $A$ of positive and negative ions with molecules of a gas in a uniform field of force was given in a paper on the "Genesis of Ions in a Gas" (J.S. Townsend, Phil. Mag. Nov. 1903) and the experiments were continued in a further paper (Dec. 1904). The apparatus previously used for these experiments with air and hydrogen has recently been used to verify the theory in the case of nitrogen and carbon dioxide, and the results of these experiments are recorded in the present paper. A detailed description of the apparatus and of the method of conducting experiments will be found in the first-mentioned paper. Briefly, the apparatus consisted of two parallel plate electrodes, one of which was zinc. In the first experiments on nitrogen and those on carbon dioxide, the other electrode was a quartz plate coated on one side with silver. Fine lines were ruled on this to allow ultra-violet light, produced by a spark between aluminium terminals, to fall on the zinc electrode. In the second set of experiments on nitrogen, a zinc plate with fine slits was substituted for the silvered quartz. These plates can be arranged at distances from $\cdot 1$ to $1 \cdot 2 \mathrm{~cm}$. apart. By means of an electrometer the currents between these plates were measured for different values of the electric intensity between them, their distance apart, and the pressure of the gas in which they were immersed. In the previous experiments the electrometer was kept at zero potential while the current was passing, by means of a condenser and potentiometer arranged as an induction balance. In the experiments here recorded the same effect was obtained by finding the rise of potential during half the time of an experiment, and then starting with the potential of the electrometer and electrode connected to it below zero by this amount. Hence during half the time of an experiment the potential-difference between the electrodes is slightly too large, and during the other half too small by nearly equal amounts. The same precautions with regard to insulation were taken as were described in the previous paper.

It has been shown that if $n_{0}$ negative ions are liberated from the zinc plate by the ultra-violet light, and travel through the gas under the action of the electric force between the plates, the number $n$ which arrive at the positive electrode

* Communicated by Prof. J. S. Townsend, F.R.S. 
536 Mr. H. E. Hurst: Genesis of Lons by Collision and

is given by

$$
n=n_{0} \frac{(\alpha-\beta) \epsilon^{(\alpha-\beta) d}}{\alpha-\beta \epsilon^{(\alpha-\beta) d}},
$$

where $\alpha$ is the number of new ions of one kind, either positive or negative, produced by a negative ion in travelling through 1 centimetre of the gas, $\beta$ is the number produced by a positive ion in travelling through 1 centimetre, and $d$ is the distance between the parallel plate electrodes. The values of $\alpha$ and $\beta$ depend upon the electric intensity $X$ between the plates, and also on the pressure $p$ of the gas. They may be determined for any values of $\mathrm{X}$ and $p$, by measuring the currents for different distances between the electrodes, $\mathbf{X}$ and $p$ being kept constant.

It was also shown that at a distance $d$, given by $\alpha-\beta \epsilon^{(\alpha-\beta) d}=0$, sparking takes place when the difference of potential between the plates is $\mathrm{X} d$, when ultra-violet light falls on the negative electrode. If $a$ is the value of $d$ satisfying this equation

$$
a=\frac{\log \alpha-\log \beta}{\alpha-\beta} .
$$

The carbon dioxide used in these experiments was prepared by the action of pure hydrochloric acid on marble. Before entering the drying apparatus it passed through glass wool and over calcium chloride. It was dried by passing through sulpburic acid and standing over phosphorus pentoxide. In the following tables $q$ is proportional to the currents determined experimentally, for fixed values of $\mathbf{X}$ and $p$, and different distances between the plates. The distance $d$ between the plates is given in centimetres, and $\mathrm{X}$ the electric intensity in volts per centimetre. $\alpha$ and $\beta$ are calculated so that the formula

$$
n=n_{0} \frac{(\alpha-\beta) \epsilon^{(\alpha-\beta) d}}{\alpha-\beta \epsilon^{(a-\beta) d}}
$$

shall be in agreement with the currents at three different distances. $n_{0}$ is taken as unity. Below the tables are given the values of $a$ determined from the equation

$$
a=\frac{\log \alpha-\log \beta}{\alpha-\beta},
$$

$\mathrm{X} a$, and the sparking-potential $\mathrm{V}$ determined experimentally. It will be seen that the theoretical values of $n$ agree with the values of the current $q$ determined experimentally. In some of the tables $\beta$ is too small to be determined with the 
Sparking-Potentials in Carbon dioxide and Nitrogen. $\quad 537$ apparatus used. In order to determine $\beta$ in these cases it would be necessary to have an apparatus which admitted of larger distances between the plates. When $\beta$ is small the formula

$$
n=n_{0} \frac{(\alpha-\beta) \epsilon^{(\alpha-\beta) d}}{\alpha-\beta \epsilon^{(\alpha-\beta) d}}
$$

reduces to $n=n_{0} \varepsilon^{a d}$. When the sparking-distance $a$ was more than $1.2 \mathrm{~cm}$., it was not possible to determine the sparking-potential, since the plates could not be separated by more than that amount.

Carbon dioxide.

Pressure 2 mms.

\begin{tabular}{|c|c|c|c|c|}
\hline & $d \ldots \ldots \ldots \ldots \ldots$ & $\cdot 1$ & $\cdot 2$ & $\cdot 3$ \\
\hline$X=1400$ & $q \ldots \ldots \ldots \ldots \ldots$ & $8 \cdot 32$ & 707 & 747 \\
\hline $\begin{array}{l}\alpha=21 \cdot 21 \\
\beta=\cdot 0085\end{array}$ & $n \ldots \ldots \ldots \ldots \ldots$ & $8 \cdot 32$ & 717 & 755 \\
\hline
\end{tabular}

Pressure $1 \mathrm{~mm}$.

\begin{tabular}{|c|c|c|c|c|c|c|}
\hline & $d \ldots \ldots \ldots \ldots \ldots$ & $\cdot 2$ & 3 & $\cdot 4$ & 5 & $\cdot 6$ \\
\hline$X=700$ & $q \ldots \ldots \ldots \ldots$ & $8 \cdot 54$ & $24 \cdot 7$ & $73 \cdot 1$ & 226 & 787 \\
\hline $\begin{array}{l}a=10.68 \\
\beta=0041\end{array}$ & $n \ldots$ & $8 \cdot 54$ & $24 \cdot 8$ & $73 \cdot 8$ & 228 & 790 \\
\hline
\end{tabular}

Pressure $1 \mathrm{~mm}$.

\begin{tabular}{|c|c|c|c|c|c|}
\hline & $d \ldots \ldots \ldots \ldots$ & 2 & $\cdot 3$ & $\cdot 4$ & $\cdot 5$ \\
\hline$X=875$ & $q \ldots \ldots \ldots \ldots \ldots$ & 107 & $36 \cdot 1$ & 129 & 643 \\
\hline $\begin{array}{l}\alpha=11.83 \\
\beta=0138\end{array}$ & $n$ & 107 & 36 & 130 & 645 \\
\hline
\end{tabular}

$a=571 . \quad \mathrm{X} a=500 . \quad \mathrm{V}=495$.

Phil. Mag. S. 6. Vol. 11. No. 64. April 1906. $2 \mathrm{~N}$ 
538 Mr. H. E. Hurst : Genesis of Ions by Collision and

Pressure $1 \mathrm{~mm}$.

\begin{tabular}{|c|c|c|c|c|}
\hline & $d \ldots \ldots \ldots \ldots \ldots$ & 2 & $\cdot 3$ & $\cdot 4$ \\
\hline$x=1050$ & $q \ldots$ & 13 & 51 & 289 \\
\hline $\begin{array}{l}\alpha=12 \cdot 6 \\
\beta=.035\end{array}$ & $n \ldots$ & 13 & $50 \cdot 4$ & 278 \\
\hline
\end{tabular}

$a=\cdot 465 . \quad \mathrm{X} a=488 . \quad \mathrm{V}=49 \mathrm{I}$.

Pressure $\cdot 5 \mathrm{~mm}$.

\begin{tabular}{|c|c|c|c|c|c|}
\hline & d $\ldots \ldots \ldots \ldots \ldots$ & $\cdot 2$ & $\cdot 4$ & 6 & 8 \\
\hline$X=525$ & $q \ldots \ldots \ldots \ldots$ & $3 \cdot 64$ & $13 \cdot 3$ & $53 \cdot 1$ & 303 \\
\hline $\begin{array}{l}a=6.41 \\
\beta=0174\end{array}$ & $n \ldots \ldots$ & $3 \cdot 64$ & $13 \cdot 3$ & 529 & 301 \\
\hline
\end{tabular}

Pressure $\cdot 5 \mathrm{~mm}$.

\begin{tabular}{|cc|c|c|c|c|c|}
\hline & $d \ldots \ldots \ldots \ldots .$. & $\cdot 2$ & 3 & 4 & $\cdot 5$ & 6 \\
\hline $\mathrm{X}=700$ & $q \ldots \ldots \ldots \ldots \ldots$ & 3.9 & $7 \cdot 8$ & $16 \cdot 6$ & $37 \cdot 4$ & $109 \cdot 2$ \\
\hline $\begin{array}{c}\alpha=6.74 \\
\beta=06\end{array}$ & $n \ldots \ldots \ldots \ldots \ldots$ & 3.9 & $7 \cdot 85$ & $16 \cdot 5$ & $37 \cdot 3$ & 107 \\
\hline
\end{tabular}

$a=706 . \quad \mathrm{X}_{a}=494 . \quad \mathrm{V}=497$.

Pressure $\cdot 5 \mathrm{~mm}$.

\begin{tabular}{|c|c|c|c|c|c|}
\hline & $d \ldots \ldots \ldots \ldots . . .$. & $\cdot 2$ & 3 & $\cdot 1$ & .5 \\
\hline$X=875$ & $q$ & $4 \cdot 58$ & $9 \cdot 63$ & $23 \cdot 2$ & 708 \\
\hline $\begin{array}{l}a=7 \cdot 5 \\
\beta=.079\end{array}$ & $n \ldots \ldots \ldots$ & $4 \cdot 58$ & $10 \cdot 14$ & $24 \cdot 2$ & $71 \cdot 2$ \\
\hline
\end{tabular}


Sparking-Potentials in Carbon dioxide and Nitrogen. 539 Pressure $\cdot 25 \mathrm{~mm}$.

\begin{tabular}{|c|c|c|c|c|c|}
\hline & $d, \ldots \ldots \ldots \ldots$ & $\cdot 2$ & $\cdot 4$ & $\cdot 6$ & $\cdot 8$ \\
\hline$X=525$ & $q \ldots$ & $2 \cdot 05$ & $4 \cdot 39$ & $9 \cdot 82$ & $25 \cdot 8$ \\
\hline $\begin{array}{l}a=355 \\
\beta=089\end{array}$ & $n \ldots \ldots . .$. & $2 \cdot 05$ & $4 \cdot 35$ & $9 \cdot 77$ & $26 \cdot 1$ \\
\hline
\end{tabular}

Pressure $4 \mathrm{mms}$.

\begin{tabular}{|ccc|c|c|c|c|c|}
\hline & $d \ldots \ldots \ldots \ldots \ldots$ & 2 & 3 & 4 & 5 & 6 \\
\hline $\mathrm{X}=700$ & $q \ldots \ldots \ldots \ldots \ldots$ & $6 \cdot 41$ & $16 \cdot 2$ & 41 & 103 & 263 \\
\hline $\begin{array}{l}a=9 \cdot 28 \\
\beta \text { mmall }\end{array}$ & $n=\epsilon^{\alpha d} \ldots \ldots \ldots$ & $6 \cdot 41$ & $16 \cdot 2$ & $41 \cdot 2$ & 104 & 262 \\
\hline
\end{tabular}

Pressure $4 \mathrm{mms}$.

\begin{tabular}{|c|c|c|c|c|c|c|}
\hline & $d^{\prime} \ldots \ldots \ldots \ldots \ldots$ & $\cdot 2$ & $\cdot 4$ & $\cdot 6$ & $\cdot 8$ & 1.0 \\
\hline$X=350$ & $q \ldots \ldots \ldots \ldots$ & $1 \cdot 64$ & $2 \cdot 72$ & $4 \cdot 41$ & $7 \cdot 28$ & $11 \cdot 7$ \\
\hline $\begin{array}{l}a=2 \cdot 47 \\
\beta \text { small }\end{array}$ & $n=e^{\alpha d}$. & $1 \cdot 64$ & 269 & $4 \cdot 41$ & $7 \cdot 25$ & $11 \cdot 9$ \\
\hline
\end{tabular}

Pressure 2 mms.

\begin{tabular}{|cc|c|c|c|}
\hline & $d \ldots \ldots \ldots \ldots .$. & 2 & 4 & $\cdot 6$ \\
\hline $\mathrm{X}=700$ & $q \ldots \ldots \ldots \ldots$. & $9 \cdot 6$ & 95 & 883 \\
\hline $\begin{array}{l}\alpha=11 \cdot 3 \\
\beta \text { small }\end{array}$ & $n=\epsilon^{\alpha d} \ldots \ldots \ldots$ & $9 \cdot 6$ & 92.5 & 881 \\
\hline
\end{tabular}

The values of $\alpha$ here obtained for the smaller values of $\frac{\mathrm{X}}{p}$ agree very closely with those obtained by Prof. Townsend (Phil. Mag. April 1903). Some doubt has been expressed as to the validity of the experiments performed on carbon dioxide, as the gas is electrolysed by spark-discharge into 


\section{Mr. H. E. Hurst: Genesis of Ions by Collision and}

carbon monoxide and oxygen, some of the oxygen being set free as ozone, which would oxidize the zinc plate. In the experiments recorded above, all the currents $q$ were measured before determining any spark-potentials, and if sparking took place during these experiments it was by accident, and was only momentary.

The largest currents used were of the order $10^{-10}$ ampere, so that if electrolysis takes place before a spark passes, an extremely small amount of gas is electrolysed. Hence the oxidation effect on the electrodes is small, and in the case of the experiments on air the only noticeable effect of oxidation was, that the currents produced by a given intensity of the light were proportionately less. The ratios of the currents. were unaltered. That is to say, oxidation causes less ions to be given off by the zinc plate under the action of ultra-violet light. As to the change of constitution of the gas, the results of the experiments show that the spark-potential can be predicted from measurements of the currents before a spark passes, so obviously it is of no importance whether the gas remains as carbon dioxide or after passage of the current contains traces of ozone. If the gas were electrolysed in quantities the last experiments of a series should not be consistent with the first, but no measurable inconsistency was ever noticed.

The nitrogen used in the first set of experiments was obtained from air by passing air and ammonia over red-hot copper, the ammonia being in excess of that required to reduce the copper oxide formed. The nitrogen so produced was again passed over red-hot copper, and then over caustic potash into the drying apparatus, where it passed through sulphuric acid, and was finally dried by remaining in contact with phosphorus pentoxide.

The following tables give the results of experiments made on gas prepared by this method.

Nitrogen prepared by First Method.

Pressure 4 mms.

\begin{tabular}{|c|c|c|c|c|c|}
\hline & $d \ldots \ldots \ldots \ldots$ & $\cdot 2$ & $\cdot 3$ & $: 4$ & $\cdot 5$ \\
\hline$X=700$ & $q \quad \ldots \ldots \ldots$ & $4 \cdot 15$ & $8 \cdot 58$ & $18 \cdot 5$ & $43 \cdot 6$ \\
\hline $\begin{array}{l}\alpha=7 \cdot 08 \\
\beta=049\end{array}$ & $n \ldots \ldots$ & $4 \cdot 15$ & 8.58 & $18 \cdot 6$ & $44 \div 3$ \\
\hline
\end{tabular}


Sparking-Potentials in Carbon dioxide and Nitrogen. 541 Pressure 4 mms.

\begin{tabular}{|c|c|c|c|c|c|}
\hline & $d \ldots \ldots \ldots$ & 2 & $\cdot 4$ & 6 & 8 \\
\hline$X=525$ & $q \cdots$ & $2 \cdot 16$ & 477 & $10 \cdot 8$ & $25 \cdot 7$ \\
\hline $\begin{array}{l}a=3.83 \\
\beta=.033\end{array}$ & $n \ldots \ldots \ldots \ldots \ldots$ & $2 \cdot 16$ & $4 \cdot 73$ & $10 \cdot 6$ & $25 \cdot 4$ \\
\hline
\end{tabular}

Pressure $2 \mathrm{mms}$.

\begin{tabular}{|c|c|c|c|c|c|}
\hline & $d \ldots \ldots \ldots \ldots \ldots$ & $\cdot 2$ & 3 & $\cdot 4$ & $\cdot 5$ \\
\hline$X=525$ & $q .$. & $4 \cdot 17$ & $8 \cdot 73$ & $19 \cdot 7$ & $50 \cdot 4$ \\
\hline $\begin{array}{l}a=7 \cdot 19 \\
\beta=\cdot 06\end{array}$ & $n \ldots \ldots \ldots$ & $4 \cdot 17$ & $9 \cdot 07$ & 20 & $49 \cdot 7$ \\
\hline
\end{tabular}

Pressure $2 \mathrm{mms}$.

\begin{tabular}{|c|c|c|c|c|c|c|}
\hline & $d \ldots \ldots \ldots \ldots$ & $\cdot 2$ & $\cdot 4$ & $\cdot 6$ & 8 & 1.0 \\
\hline$X=350$ & $q \ldots \ldots \ldots \ldots$ & 201 & 4.07 & 8.5 & 18.7 & $45 \cdot 4$ \\
\hline $\begin{array}{l}\alpha=3.54 \\
\beta=025\end{array}$ & $n \ldots \ldots \ldots \ldots$ & $2 \cdot 01$ & $4 \cdot 16$ & $8 \cdot 73$ & $18 \cdot 8$ & $44 \cdot 7$ \\
\hline
\end{tabular}

Pressure $1 \mathrm{~mm}$.

\begin{tabular}{|c|c|c|c|c|c|c|}
\hline & $d \ldots \ldots \ldots \ldots \ldots$ & $\cdot 2$ & $\cdot 4$ & $\cdot 6$ & 7 & $\cdot 8$ \\
\hline $\mathbf{X}=350$ & $q$. & $2 \cdot 44$ & $6 \cdot 46$ & $18 \cdot 9$ & $37 \cdot 2$ & 112 \\
\hline $\begin{array}{l}a=4.42 \\
\beta=\cdot 099\end{array}$ & $n \ldots$. & $2 \cdot 44$ & $6 \cdot 30$ & 18.8 & $37 \cdot 4$ & 107 \\
\hline
\end{tabular}


542 Mr. H. E. Hurst : Genesis of Ions by Collision and

Pressure $1 \mathrm{~mm}$.

\begin{tabular}{|c|c|c|c|c|c|}
\hline & $d \ldots \ldots \ldots . . . .$. & $\cdot 2$ & 3 & $\cdot 4$ & $\cdot 5$ \\
\hline$X=525$ & $q \ldots \ldots \ldots \ldots$ & $3 \cdot 72$ & $7 \cdot 63$ & $16 \cdot 9$ & $48 \cdot 5$ \\
\hline $\begin{array}{l}a=6.41 \\
\beta=\cdot 15\end{array}$ & $n \ldots \ldots$ & $3 \cdot 72$ & $7 \cdot 55$ & $16 \cdot 95$ & $48 \cdot 1$ \\
\hline
\end{tabular}

Pressure $\cdot 5 \mathrm{~mm}$.

\begin{tabular}{|c|c|c|c|c|c|c|}
\hline & $d \ldots \ldots \ldots \ldots . . . . .$. & $\cdot 2$ & $\cdot 4$ & $\cdot 6$ & 8 & $1 \cdot 0$ \\
\hline$X=2625$ & $q \ldots \ldots \ldots \ldots$ & 1.92 & $3 \cdot 82$ & $7 \cdot 61$ & $17 \cdot 1$ & $49 \cdot 5$ \\
\hline $\begin{array}{l}\alpha=3 \cdot 23 \\
\beta=\cdot 074\end{array}$ & $n$ & 1.92 & $3 \cdot 77$ & $7 \cdot 68$ & $17 \cdot 2$ & $49 \cdot 8$ \\
\hline
\end{tabular}

Pressure 4 mms.

\begin{tabular}{|c|c|c|c|c|}
\hline & $d \ldots \ldots \ldots \ldots$ & $\cdot 2$ & 6 & $1 \cdot 0$ \\
\hline$X=350$ & $q$ & $1 \cdot 31$ & $2 \cdot 25$ & $3 \cdot 85$ \\
\hline $\begin{array}{l}\alpha=1 \cdot 35 \\
\beta \text { small }\end{array}$ & $n=\epsilon^{a d} \ldots \ldots \ldots$ & $1 \cdot 31$ & $2 \cdot 25$ & 3.86 \\
\hline
\end{tabular}

Pressure $8 \mathrm{mms}$.

\begin{tabular}{|c|c|c|c|c|}
\hline & d $\ldots \ldots \ldots \ldots$ & $\cdot 2$ & $\cdot 6$ & $1 \cdot 0$ \\
\hline$X=350$ & $q \ldots \ldots \ldots \ldots$ & 103 & $1 \cdot 12$ & $1 \cdot 18$ \\
\hline $\begin{array}{l}a=\cdot 17 \\
\beta \text { small }\end{array}$ & $n=\varepsilon^{\alpha d}$ & $1 \cdot 03$ & $1 \cdot 10$ & $1 \cdot 18$ \\
\hline
\end{tabular}


Pressure $16 \mathrm{mms}$.

\begin{tabular}{|c|c|c|c|c|}
\hline & $d \ldots \ldots \ldots \ldots \ldots$ & $\cdot 1$ & $\cdot 3$ & $\cdot 5$ \\
\hline$X=700$ & $q \ldots \ldots \ldots$ & 1.03 & $1 \cdot 075$ & $1 \cdot 17$ \\
\hline $\begin{array}{l}\alpha=\cdot 32 \\
\beta \text { small }\end{array}$ & $n=\boldsymbol{\varepsilon}^{\alpha d}$. & $1 \cdot 03$ & $1 \cdot 1$ & $1 \cdot 17$ \\
\hline
\end{tabular}

In order to test whether hydrogen was present in the gas in appreciable quantities, some more nitrogen was prepared by the same method, and its specific gravity carefully determined.

The mean of two experiments gave .971 as its sp. gr., which was probably correct to $\cdot 2$ per cent., as an orror of 3 milligrams in weighing would only have produced 1 per cent. error in the result. The sp. gr. of pure nitrogen is $\cdot 972$.

In the following experiments the nitrogen used was prepared by a similar method to that used by Lord Rayleigh for obtaining nitrogen from air. Air was passed through strong ammonia, over hot copper, through dilute sulphuric acid to remove excess of ammonia, then over hot copper oxide to a gas-holder, where it stood over water containing sulphuric acid. This gas was afterwards passed through a solution of caustic potash, and again over heated freshly reduced copper in a long tube, and copper oxide in another long tube. The copper oxide was kept red-hot, and the first portions of nitrogen were used to wash the receiver, which was exhausted each time. After an hour some nitrogen was collected and the receiver sealed. From the receiver the gas passed into the drying apparatus as before. Lord Rayleigh tested the efficacy of this method of removing hydrogen, by allowing a constant stream of hydrogento mix with his gas before it passed over copper oxide, and found no hydrogen in the gas at the finish.

In order to avoid difficulties arising from the burning away of the silver on the positive electrode, a zinc plate perforated with fine slits was used. The following results. were obtained.

Pressure 4 mms.

\begin{tabular}{|c|c|c|c|c|c|c|}
\hline & $d$ & 2 & $\cdot 3$ & $\cdot 4$ & 5 & 6 \\
\hline$X=700$ & $q \ldots \ldots$ & $4 \cdot 2$ & 8.86 & $19 \cdot 2$ & $44 \cdot 2$ & 123 \\
\hline $\begin{array}{l}a=7 \cdot 12 \\
\beta=044\end{array}$ & $n \ldots \ldots \ldots \ldots$ & 4.2 & $8 \cdot 85$ & 18.9 & $43 \cdot 4$ & 123 \\
\hline
\end{tabular}


544 Mr. H. E. Hurst: Genesis of Ions by Collision and

Pressure $2 \mathrm{mms}$.

\begin{tabular}{|cc|c|c|c|c|}
\hline & $d \ldots \ldots \ldots \ldots .$. & -2 & -3 & $\cdot 4$ & $\cdot 5$ \\
\hline $\mathrm{X}=525$ & $q \ldots \ldots \ldots \ldots \ldots$ & 3.94 & $7 \cdot 95$ & 17 & $42 \cdot 7$ \\
\hline $\begin{array}{l}a=6.76 \\
\beta=08\end{array}$ & $n \ldots \ldots \ldots \ldots \ldots$ & 3.94 & $8 \cdot 05$ & $17 \cdot 2$ & $41 \cdot 9$ \\
\hline
\end{tabular}

Pressure $1 \mathrm{~mm}$.

\begin{tabular}{|c|c|c|c|c|c|}
\hline & $d \ldots \ldots \ldots \ldots \ldots$ & $\cdot 2$ & 3 & $\cdot 4$ & 5 \\
\hline$X=525$ & $q \ldots \ldots$ & 3.58 & $7 \cdot 15$ & $15 \cdot 9$ & $54 \cdot 3$ \\
\hline $\begin{array}{l}\alpha=6.18 \\
\beta=\cdot 194\end{array}$ & $n \ldots \ldots \ldots \ldots$ & $3 \cdot 58$ & $7 \cdot 20$ & $16 \cdot 3$ & $52 \cdot 1$ \\
\hline
\end{tabular}

A satisfactory agreement may be found between these tables and those for the nitrogen which was first used.

Besides these experiments a number of determinations of the spark-potential were made, for different values of the pressure and distance between the plates.

The effect of mixing small quantities of oxygen with the gas was also determined. The sparking-potentials were determined by connecting in series with the parallel plates a battery of small cells, a voltmeter, and a resistance-box.

In the experiments on carbon dioxide and the first sample of nitrogen the total external resistnnce was about 50,000 ohms, but in the later experiments on nitrogen 68,000 or 98,000 ohms. This increase of resistance raised the sparking-potential about 2 volts.

In all the determinations the lowest potential which gave a spark when ultra-violet light of small intensity fell on the negative electrode is given, and this is the potential $\mathrm{V}$ in the preceding tables. But in some of the experiments the potential required to give a spark without the action of ultra-violet light was also determined. After one determination had been made and a spark had passed, it was found necessary to wait a 
Sparking-Potentials in Carbon dioxide and Nitrogen. $\quad 545$

few seconds, and in no case was sparking allowed to be more than momentary. It was found that unless these conditions were complied with, other phenomena occurred which made the determination of the sparking-potential uncertain. These phenomena were especially noticeable in the neighbourhood of the minimum sparking-potential, and at values of $p d$ less than the critical value, $p$ being the pressure and $d$ the distance between the plates.

The results of all the experiments are collected in the following tables, in which are given the potentials required to produce sparks with ultra-violet light acting, the potentials required without light, and in some cases the potentials calculated for the distance

$$
a=\frac{\log x-\log \beta}{\alpha-\beta} .
$$

Carbon dioxide.

\begin{tabular}{|c|c|c|c|c|c|}
\hline $\begin{array}{c}\text { Pressure. } \\
p\end{array}$ & $\begin{array}{l}\text { Distance } \\
\text { between } \\
\text { platea } d .\end{array}$ & $p d$ & $\begin{array}{c}\text { Calculated } \\
\text { potential. } \\
\mathbf{X} d .\end{array}$ & $\begin{array}{c}\text { Spark potential } \\
\text { with light. } \\
\text { V. }\end{array}$ & $\begin{array}{l}\text { Spark potential } \\
\text { without light. }\end{array}$ \\
\hline $\mathrm{mm}_{2}$. & cro. & .738 & $\begin{array}{c}\text { volts. } \\
516\end{array}$ & volts. & volts. \\
\hline 1 & .736 & .736 & 516 & 509 & 525 \\
\hline 1 & .571 & 571 & 500 & 495 & 509 \\
\hline 1 & $\cdot 465$ & .465 & 488 & 491 & \\
\hline .5 & .929 & .464 & 488 & 485 & \\
\hline-5 & $\cdot 706$ & $\cdot 353$ & 494 & 497 & \\
\hline$\cdot 5$ & 613 & 306 & 537 & 530 & 542 \\
\hline$\cdot 25$ & 1.062 & 265 & 558 & 564 & \\
\hline
\end{tabular}

Nitrogen prepared by first method.

\begin{tabular}{|c|c|c|c|c|c|}
\hline$p$ & $d$ & $p d$. & $\mathbf{X} d$ & $\underset{\text { (with light). }}{\mathbf{V}}$ & $\begin{array}{c}\text { Spark } \\
\text { potential } \\
\text { without light. }\end{array}$ \\
\hline $\begin{array}{l}\text { min. } \\
4 \\
\mathbf{4} \\
\mathbf{2} \\
\mathbf{2} \\
1 \\
1 \\
1_{5}\end{array}$ & $\begin{array}{c}\mathrm{cm} . \\
708 \\
1 \cdot 236 \\
1 \cdot 41 \\
\cdot 67 \\
.88 \\
-601 \\
1 \cdot 195\end{array}$ & $\begin{array}{c}2 \cdot 832 \\
4 \cdot 944 \\
2 \cdot 82 \\
1 \cdot 34 \\
\cdot 88 \\
\cdot 601 \\
\cdot 597\end{array}$ & $\begin{array}{c}\text { volts. } \\
496 \\
649 \\
493 \\
352 \\
308 \\
316 \\
314\end{array}$ & $\begin{array}{l}349 \\
303 \\
311\end{array}$ & $\begin{array}{l}305 \\
311\end{array}$ \\
\hline
\end{tabular}


546 Mr. H. E. Hurst: Genesis of lons by Collision and

Nitrogen prepared by second method.

\begin{tabular}{|c|c|c|c|c|c|}
\hline$p$. & $d$ & $p d$. & $\mathrm{X} d$ & $\begin{array}{c}\nabla \\
\text { (with light). }\end{array}$ & $\begin{array}{c}\text { Spark } \\
\text { potential } \\
\text { without light. }\end{array}$ \\
\hline $\begin{array}{l}4 \\
4 \\
4 \\
2 \\
2 \\
2 \\
2 \\
2\end{array}$ & $\begin{array}{l}\cdot 72 \\
.708 \\
.6 \\
.58 \\
.65 \\
.665 \\
.85 \\
.67\end{array}$ & $\begin{array}{l}2 \cdot 88 \\
2 \cdot 832 \\
2 \cdot 4 \\
1 \cdot 16 \\
1 \cdot 30 \\
1 \cdot 33 \\
1 \cdot 70 \\
1 \cdot 34\end{array}$ & 349 & $\begin{array}{l}507 \\
504 \\
460 \\
332 \\
339 \\
344 \\
382 \\
329\end{array}$ & $\begin{array}{l}512 \\
504 \\
464 \\
334 \\
343 \\
346 \\
384 \\
345\end{array}$ \\
\hline $\begin{array}{l}1 \\
1 \\
1 \\
1 \\
1 \\
1\end{array}$ & $\begin{array}{l}\cdot 4 \\
\cdot 5 \\
.58 \\
\cdot 601 \\
.868 \\
1 \cdot 0\end{array}$ & $\begin{array}{l}\cdot 4 \\
\cdot 5 \\
\cdot 58 \\
\cdot 601 \\
\cdot 868 \\
1 \cdot 0\end{array}$ & 304 & $\begin{array}{l}330 \\
310 \\
300 \\
298 \\
300 \\
310\end{array}$ & $\begin{array}{l}336 \\
314 \\
304 \\
303 \\
306 \\
314\end{array}$ \\
\hline \multicolumn{6}{|c|}{ Mixture of Nitrogen and $1 \cdot 1$ per cent. of Oxygen. } \\
\hline $\begin{array}{l}4 \\
4 \\
4 \\
2 \\
2 \\
2 \\
2 \\
1\end{array}$ & $\begin{array}{l}\cdot 72 \\
\cdot 708 \\
\cdot 6 \\
\cdot 58 \\
\cdot 65 \\
\cdot 85 \\
.665 \\
\cdot 601\end{array}$ & $\begin{array}{l}2 \cdot 88 \\
2 \cdot 832 \\
2 \cdot 4 \\
1 \cdot 16 \\
1 \cdot 30 \\
1 \cdot 70 \\
1 \cdot 330 \\
\cdot 601\end{array}$ & & $\begin{array}{l}516 \\
514 \\
472 \\
335 \\
342 \\
392 \\
341 \\
\ldots\end{array}$ & $\begin{array}{l}518 \\
520 \\
476 \\
343 \\
350 \\
398 \\
349 \\
302\end{array}$ \\
\hline \multicolumn{6}{|c|}{ Mixture of Nitrogen and 5 per cent. Oxygen. } \\
\hline 1 & $\begin{array}{l}\cdot 4 \\
\cdot 5 \\
\cdot 58 \\
\cdot 601 \\
.65 \\
.70 \\
.8 \\
.868 \\
1 \cdot 0\end{array}$ & $\begin{array}{l}\cdot 4 \\
\cdot 5 \\
\cdot 58 \\
\cdot 601 \\
.65 \\
\cdot 70 \\
.80 \\
.868 \\
1.0\end{array}$ & & $\begin{array}{l}369 \\
334 \\
320 \\
\ldots 3 \\
316 \\
312 \\
316 \\
320 \\
324\end{array}$ & $\begin{array}{l}371 \\
338 \\
324 \\
320 \\
320 \\
316 \\
320 \\
324 \\
332\end{array}$ \\
\hline
\end{tabular}

The sparking-potentials for nitrogen do not agree with those obtained by Strutt (Phil. Trans. 193, p. 377, 1900). He found that the sparking-potential of nitrogen varied considerably with different samples of gas, although prepared by the same method. This he attributed to the presence of 
Sparking-Potentials in Carbon dioxide and Nitrogen. $\quad 547$

traces of oxygen, since if the gas was passed repeatedly through a liquid alloy of sodium and potassium, a constant minimum potential of 251 volts was obtained. The volume of the apparatus used was small, and before determining a sparking-potential the gas was sparked through vigorously. If the apparatus had previously been used for the experiments on hydrogen, it is possible that the sparking would drive out some hydrogen occluded in them, which in a small volume might form an appreciable percentage of the gas present. This would tend to lower the spark-potential and make its determination uncertain. In the determinations of sparkpotentials described in this paper it was found that in the neighbourhood of the minimum spark-potential, the sparkpotential was sometimes affected to the extent of 6 or 8 volts by the previous passage of a current through the gas, and before the potential could be again determined some time must elapse if the results were to be concordant, so that all potentials were determined without sparking having taken place immediately before.

It will be seen by comparison of the tables given for nitrogen prepared by the methods mentioned, that there is not a great difference between the results obtained in both cases. The tables of sparking-potentials show also that a small percentage of oxygen only produces small differences in the sparking-potentials, and that 5 per cent. produces more effect than 1 per cent. These facts seem to show that small quantities of impurities do not produce disproportionate effects. If this be true, the variations in the spark-potential of nitrogen are not produced by minute traces of impurity but are due to other causes. Further experiments in this direction are to be attempted shortly.

The accompanying curves, figs. 1 and 2 , show the relation between the sparking-potential and the product of the pressure of the gas $p$ and the distance between the plates $d$, for carbon dioxide and nitrogen. As the spark-potential determined with ultra-violet light falling on the negative electrode was in most cases nearly the same as that determined without the light, one curve only has been drawn in each case, through the points representing the potentials obtained with the light.

The theoretical values of the spark-potential calculated from the formula before given are also indicated. 
548 Mr. H. E. Hurst: Genesis of Tons by Collision and

Fig. 1.-Carbon dioxide.

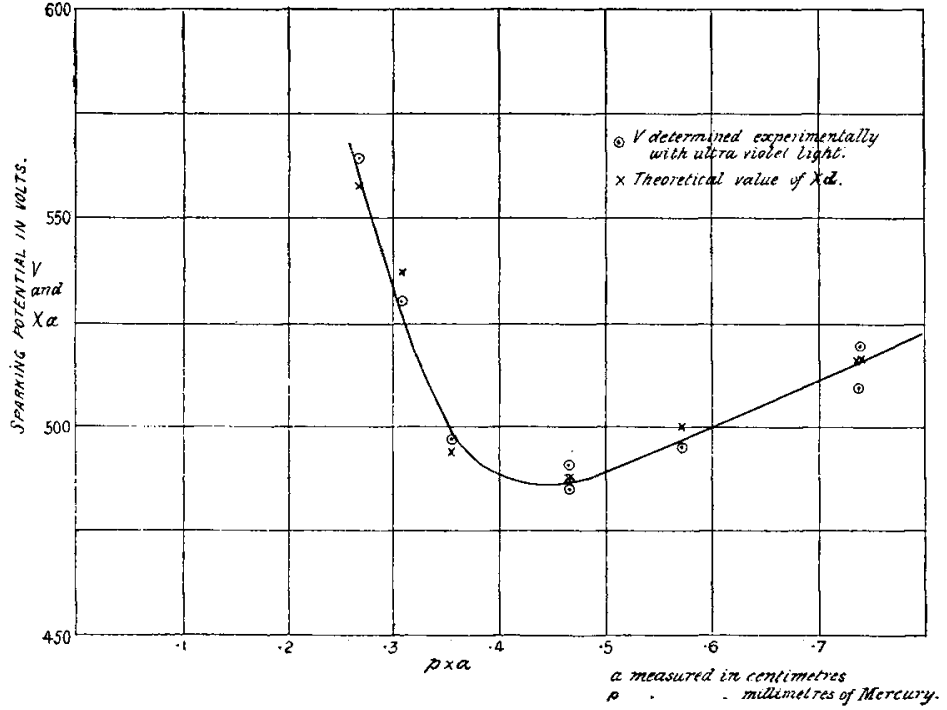

Fig. 2.-Nitrogen.




Sparking-Potentials in Carlon dioxide and Nitrogen. $\quad 549$

Fig. 3 shows the curves obtained with the different samples of nitrogen and also the effect of small quantities of oxygen.

Fig. 3.

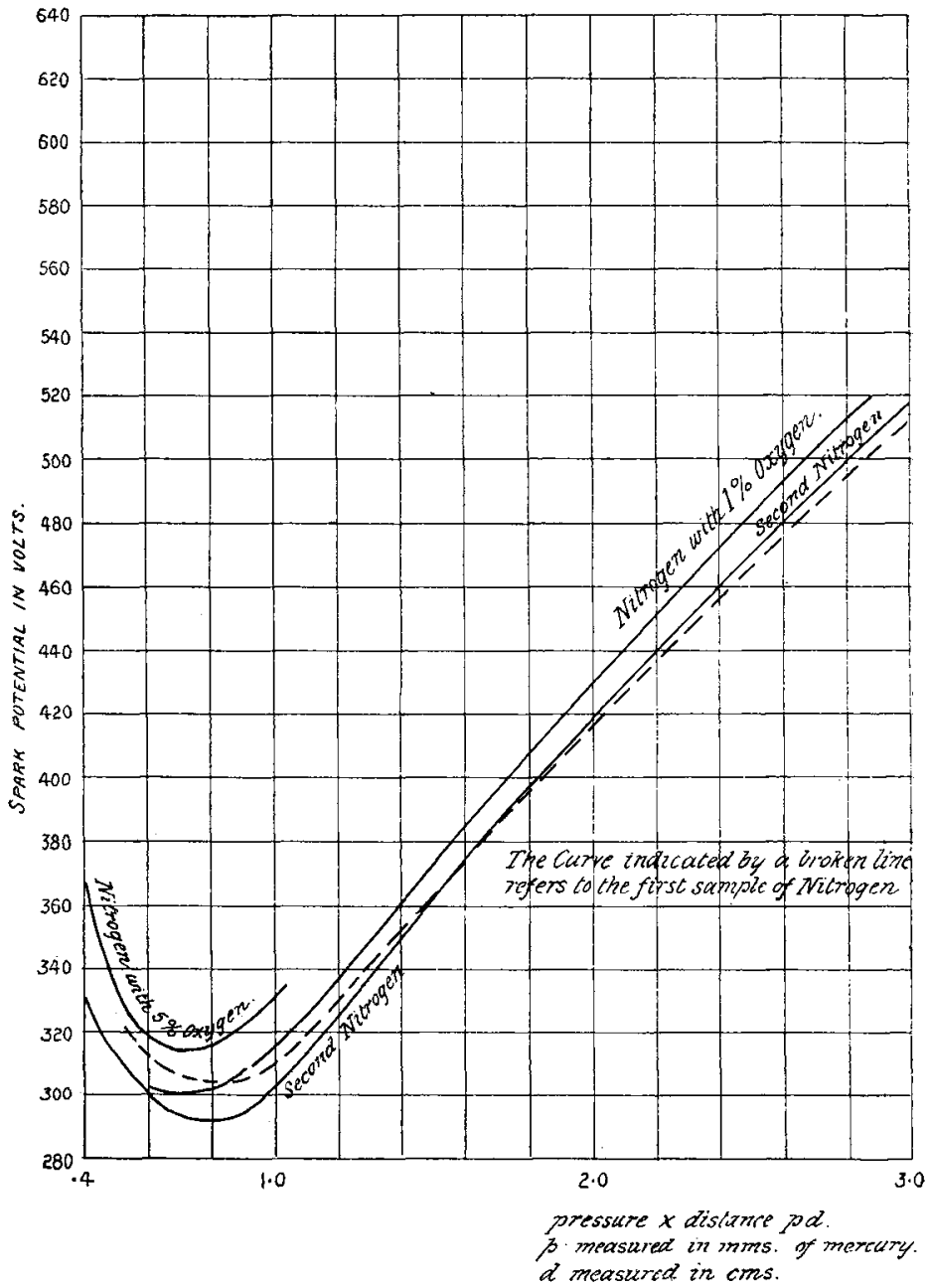

The theoretical investigations are intended to apply to cases where the pressure is not less than the critical pressure, and it will be noticed that the effect of small impurities is negligible at the higher pressures.

The minimum spark-potential for the first nitrogen is about 302 volts, for the second about 295 volts. The gas containing 
5 per cent. of oxygen gives a minimum spark-potential of about 312 volts.

In the tables before given it will be noticed that the theoretical values of $n$, calculated from the formula

$$
n=n_{0} \frac{(\alpha-\beta) \epsilon^{(\alpha-\beta) d}}{\alpha-\beta \epsilon^{(\alpha-\beta) d}}
$$

agree with the values of the current $q$ determined experimentally, so that the theory furnishes an explauation of the currents which take place in a gas before sparking occurs. In preceding papers on this subject it was shown that $\frac{\alpha}{p}$ and $\frac{\beta}{p}$ are functions of $\frac{\mathrm{X}}{p}$, and the accompanying curves, figs. 4 and 5 , show the relations between these variables. In

Fig. 4.

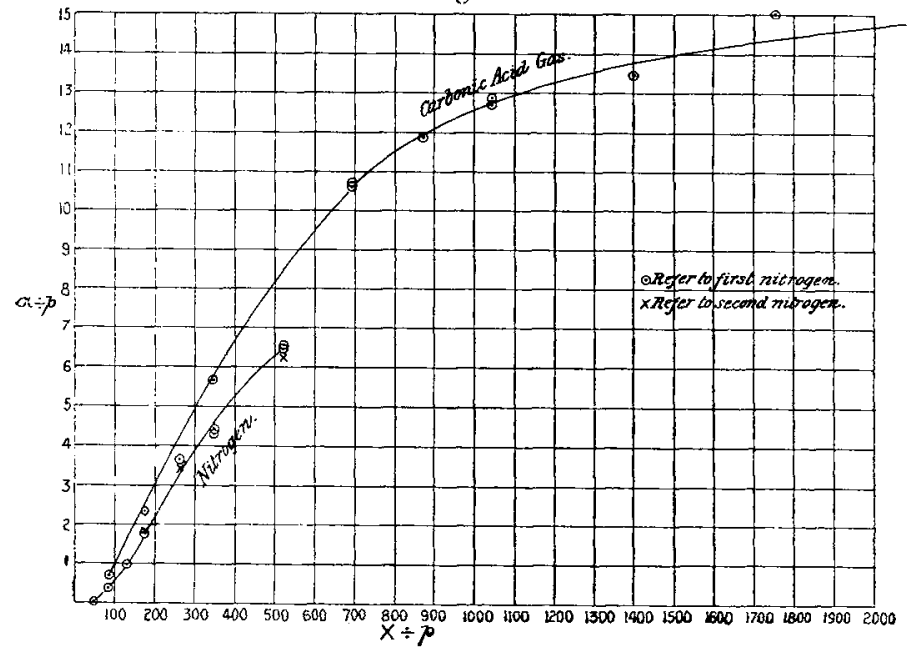

those for nitrogen, the curves relate to the first set of experiments, and the values for the second experiments were put in after the curves were drawn. It will be seen that the discrepancy between the two sets is comparable with the errors of experiment, so that we shall give the following conclusions drawn from the results of the first experiments, since it seems that the presence of small quantities of impurities only produces small errors. The larger values of $\alpha$ can be represented by the formula $\frac{\alpha}{p}=\mathrm{N} \epsilon^{-\frac{\mathrm{NV} p}{\mathbf{x}}}$ (J. S. Townsend, Phil. Mag. April 1903), obtained on the assumption that new ions are formed by collision when the colliding ion has a velocity due to a fall of potential $\nless \mathrm{V}$. 
Sparking-Potentials in Carbon diowide and Nitrogen. $\quad 551$ $\mathrm{N}$ is the average number of collisions of a negative ion in moving through a centimetre of gas at $1 \mathrm{~mm}$. pressure. In

Fig. 5.



the case of carbon dioxide when $\mathrm{N}=17 \cdot 4$ and $\mathrm{V}=18.8$ volts, the values of $a$ calculated from the above formula agree with those obtained from the curve for values of $\frac{\mathrm{X}}{p}$ between 2000 and 350. For nitrogen the numbers $N=13 \cdot 6$ and $V=28 \cdot 5$ give values of $a$ agreeing with experiment for values of $\frac{\mathrm{X}}{p}$ hetween 175 and 525. For the smaller values of $\frac{\alpha}{p}$ it is necessary to suppose that some new ions are formed when the velocity on collision is less than that due to the critical fall of potential V.

The values of $\mathrm{N}$ and $\mathrm{V}$ for nitrogen do not differ much from those for air given in the paper previously mentioned, and the curve there given falls between those for nitrogen and carbon dioxide. It is not possible to represent $\frac{\beta}{p}$ within the range of experiments performed by a formula of the type $\mathrm{N} \varsigma^{-\frac{N V p}{\mathrm{X}}}$. Perhaps, as in the case of the smaller 
values of $\frac{\alpha}{p}$, one could be obtained on the hypothesis that some collisions after velocities less than a critical velocity are productive of new ions. This view obtains some support from the fact that the curves for $\frac{\beta}{p}$ are very similar to those portions of the $\frac{\alpha}{p}$ curves corresponding to the smaller values of $\frac{\mathrm{X}}{p}$.

It will be noticed that the values of $\alpha$ for $\mathrm{CO}_{2}$ and niirogen are of the same order of magnitude, but that $\beta$ is much smaller in $\mathrm{CO}_{2}$ than in nitrogen. It has been shown that all ions have the same charge. Now, if we assume that a positive ion is approximately of the same size as the molecules of the gas in which it is formed, and a negative ion very small compared with these, a positive ion in travelling a given distance will make about four times as many collisions as a negative ion in travelling the same distance. Therefore a negative ion in a gas at $1 \mathrm{~mm}$. pressure will make approximately the same number of collisions per centimetre as a positive ion in the same gas at $25 \mathrm{~mm}$. pressure. In $\mathrm{CO}_{2}$ at $1 \mathrm{~mm}$. pressure the number of collisions made by a negative ion in going $1 \mathrm{~cm}$. is 17.4 , and when the electric intensity is $175, \alpha$ is $2 \cdot 4$. Now at $\frac{1}{4} \mathrm{~mm}$. pressure $\beta$ is $\cdot 001$ for the same force. So that for an equal number of collisions under the same conditions, a negative ion makes about 2400 times as many new ions in $\mathrm{CO}_{2}$ as a positive ion. In nitrogen a negative ion would make about $17 \cdot 4$ collisions per centimetre at a pressure of $1.28 \mathrm{mms}$. For the same electric intensity 1.75, $\alpha$ is 1.28 . At $\cdot 32 \mathrm{~mm}$. pressure the number of collisions of a positive ion in nitrogen would be approximately the same as in the cases already considered, and for intensity $175, \beta$ is about 058 . Under these conditions then, a negative ion in nitrogen produces 22 times as many new ions as a positive ion in going a given distance. Hence the positive ion in nitrogen differs less from the negative ion than does the positive ion in $\mathrm{CO}_{2}$. Since all negative ions are the same, this will be the case if negative ions are small compared with positive ions, and positive ions in nitrogen smaller than those in carbon dioxide. There is a considerable difference between the values of $\beta$ for nitrogen and those for air, $\beta$ being larger in nitrogen than in air. From this it would seem that $\beta$ for oxygen is small.

In conclusicn, I wish to express my thanks to Professor Townsend for his advice and assistance during the course of the experiments, and also to Dr. ㄱ. B. B. Baker for his criticism of some points connected with the preparation of the gases. 